\title{
Reducing the energy consumption of the conveyor transport system of mining enterprises
}

\author{
Ruslan Kiriia ${ }^{1, *}$, and Leonid Shyrin ${ }^{2}$ \\ ${ }^{1}$ Institute of Geotechnical Mechanics named by N. Poljakov of National Academy of Sciences of \\ Ukraine, 49005, Dnipro, Simferopolska Str., 2a, Ukraine \\ ${ }^{2}$ Dnipro University of Technology, Ukraine, 49000, Dnipro, Dmytra Yavornytskoho Ave., 19, \\ Ukraine
}

\begin{abstract}
The article deals with the actual issue of reducing the energy consumption of the mining enterprises conveyor transport system. The analysis of energy loss by conveyor belt during transportation of bulk load is given. A comparative analysis of energy losses in the cases of regulation and non-regulation of the speed of the conveyor belt is given. It was found that when regulating the speed of conveyor belt in the case of reducing the value of the load flow entering to the conveyor by half the loss of electricity for the transportation of load is reduced by $30 \%$ compared to the unregulated speed of the belt. The energy efficiency criterion of the conveyor transport system is determined, which coincides with the specific energy capacity equal to the ratio of the average energy capacity of the transportation of load to the transport system average carrying capacity. It has also been established that for conveyor transport systems conveyorbunker-conveyor, taking into account the downtime of conveyor equipment while regulating the speed of conveyor, energy losses are reduced by $23 \%$. The research results can be used to create a computer control system for the operation of conveyor transport systems.
\end{abstract}

\section{Introduction}

In connection with the rise in price of electricity at mining enterprises, the problem of reducing energy costs during the transportation of bulk load by belt conveyors arose. The main reason for the increase in unproductive energy consumption during transportation of load by the conveyor transport system is the underload of the conveyor, due to the unevenness of load flow entering the transport system, as well as downtime of the conveyor equipment for emergency, technological and organizational reasons. In this case, the conveyors in the conveyor transport system for a long time work with a load much smaller than the nominal load, or no load at all.

One of the methods to reduce energy consumption when changing the value of load flow entering the transport system is to regulate the speed of the conveyor belt $[1,2]$.

\footnotetext{
*Corresponding author: kiriya_igtm@ukr.net
} 
Currently, the speed of the conveyor belt is controlled by a frequency-controlled drive. With this method, in the case of an increase in the value of the load flow entering the conveyor, the speed of the conveyor belt increases, and with a decrease in the value of the load flow, the speed of the belt decreases.

The issues of reducing the energy consumption of the system of underground conveyor transport of coal mines are devoted to the work [1-6].

In these works, a comparison of the energy efficiency of a conveyor with adjustable and non-adjustable belt speed is given. At the same time, different values are taken as the criterion of energy efficiency in these works. In addition, in these works, the physics of the loss of electricity during the transportation of bulk load according to the conveyor belt is not sufficiently disclosed.

In this paper, the analysis of electric power losses during the transportation of bulk load through a belt conveyor, as well as the system conveyor-bunker-conveyor is presented, and on the basis of this, the rationale for the use of a belt conveyor with adjustable belt speed is given. In addition, the parameters of the optimal control of the speed of the conveyor belt are defined.

\section{Methods}

We first determine how much it is necessary to reduce the speed of the conveyor belt while reducing the load flow to it, in order to significantly reduce the energy consumption for the load transportation.

The drive power of a conveyor belt $N$, going to transport load, according to [7] is determined by the formula:

$$
N=\frac{W \cdot v_{b}}{1000 \eta},
$$

where $W$ is the force on the drive drum of the conveyor, $\mathrm{N} ; v_{b}$ is conveyor belt speed, $\mathrm{m} / \mathrm{s} ; \eta$ is the efficiency of the drive.

The force on the drive drum consists of the component forces of the weight of the load and the belt, the forces of resistance to the movement of the load and the belt along the roller conveyors, as well as local resistances during the rotation of the drums and in the reloading nodes. According to [7], this force is determined by the formula:

$$
W=k_{1}\left(q_{l}+q_{r}^{\prime}+q_{r}^{\prime \prime}+2 q_{b}\right) L \omega^{\prime} \cos \alpha+q_{l} L \sin \alpha,
$$

where $q_{l}, q_{b}$ is the linear weight of the load and the conveyor belt, respectively, $\mathrm{N} / \mathrm{m} ; q^{\prime}{ }_{r}$, $q^{\prime \prime}{ }_{r}$ is linear weights of the rotating parts of the roller supports of the upper and lower branches of the conveyor belt, $\mathrm{N} / \mathrm{m} ; L$ is the length of the conveyor, $\mathrm{m}$; $\alpha$ is the angle of inclination of the conveyor, $\mathrm{m}$; $\omega^{\prime}$ is the coefficient of resistance to the movement of the belt with a load along the roller supports of the belt conveyor; $k_{1}$ is coefficient taking into account local resistance to movement of the conveyor belt.

Substituting (2) into (1), after the conversion we get:

$$
N=\frac{L}{1000 \eta}\left[v_{b} q_{l}\left(k_{1} \omega^{\prime} \cos \alpha+\sin \alpha\right)+k_{1} v_{b}\left(q_{r}^{\prime}+q_{r}^{\prime \prime}+2 q_{b}\right) \omega^{\prime} \cos \alpha\right] .
$$

According to [6], the linear weight of the load on the conveyor belt: 


$$
q_{l}=\frac{Q g}{3.6 v_{b}},
$$

where $Q$ is the current productivity of the conveyor, i.e. the value of the load flow to the conveyor, $\mathrm{t} / \mathrm{hr} ; \mathrm{g}$ is acceleration of gravity, $\mathrm{m} / \mathrm{s}^{2}$.

In view of (4), expression (3) has the form:

$$
N=\frac{L g}{1000 \eta}\left[\frac{Q}{3.6}\left(k_{1} \omega^{\prime} \cos \alpha+\sin \alpha\right)+k_{1} v_{b}\left(q_{r}^{\prime}+q_{r}^{\prime \prime}+2 q_{b}\right) \omega^{\prime} \cos \alpha\right]
$$

or

$$
N=A Q+B v_{b}
$$

where $A=\frac{L g}{3600 \eta}\left(k_{1} \omega^{\prime} \cos \alpha+\sin \alpha\right) ; B=\frac{L g}{1000 \eta} k_{1}\left(q_{r}^{\prime}+q_{r}^{\prime \prime}+2 q_{b}\right) \omega^{\prime} \cos \alpha$.

In this case, the rated drive power of the conveyor is determined by the formula:

$$
N_{n}=A Q_{n}+B v_{b},
$$

where $Q_{n}$ is the nominal (technical) productivity of the conveyor, $\mathrm{t} / \mathrm{hr}$.

The value of $Q_{n}$ according to (4) we find the formula:

$$
Q_{n}=0.36 q_{l \max } v_{b} .
$$

The first term in the formula (6) determines the power of the drive of the belt conveyor, which is necessary to overcome the forces of resistance to the movement of the load along the roller supports and the force of gravity when the load is moved by the belt conveyor. The second term defines the drive power of the belt conveyor, necessary for overcoming the resistance forces of the belt movement along the conveyor roller supports and the resistance forces of the rotating parts of the rollers.

From (6) it follows that with a decrease in the value of the load flow $Q$ entering the conveyor, under the condition that the belt speed is constant, the conveyor drive power consumed to move the load decreases, and the conveyor drive power consumed to move the belt and the rotation of the rollers does not change.

With a decrease in the belt speed $v_{b}$ at a constant value of the load flow $Q$ according to (4), the linear load $q_{l}$ of the conveyor increases and reaches the maximum value $q_{l \text { max }}$ when the speed of the conveyor belt is equal to $v_{\min } \leq v_{b}$. When this is $q_{l \max }$ determined by the formula:

$$
q_{l \max }=\frac{Q g}{3.6 v_{\min }} .
$$

From the last equality we have:

$$
v_{\min }=\frac{Q g}{3.6 q_{l \max }} .
$$

According to [7], the maximum linear load of the conveyor $q_{l \max }$ is determined by the maximum cross-sectional area of the load on the belt and depends on the width of the conveyor belt, the angle of inclination of the rollers and is a constant value for this conveyor.

Substituting (8) into (6), we get: 


$$
N=A Q+B \frac{Q g}{3.6 q_{l \max }} .
$$

It follows from (9) that when the value of the load flow $Q$ entering the conveyor changes, the drive power of the conveyor for moving the belt and rotating the rollers is minimal if the belt speed takes the minimum value $v_{\min }$ at which the linear load takes the maximum value $q_{l}=q_{l \text { max }}$.

Thus, optimal control of the speed of the conveyor belt from the point of view of energy consumption will be such a control, at which the belt speed will be minimal, and the linear load on the conveyor will be maintained at its maximum:

$$
q_{l}=q_{l \max }=\text { const. }
$$

In this case, according to expression (2), the force on the drive takes a constant maximum value:

$$
W_{m}=k_{1}\left(q_{l \max }+q_{r}^{\prime}+q_{r}^{\prime \prime}+2 q_{b}\right) L \omega^{\prime} \cos \alpha+q_{l \max } L \sin \alpha .
$$

The speed of the conveyor belt can be controlled using an asynchronous motor with a short-circuited rotor with a proportional change in the values of frequency and voltage on the electric motor. This ensures a constant maximum torque on the electric motor [2].

Now we define the specific energy consumption of transportation of the conveyor with unregulated and adjustable speeds of the conveyor belt according to [5]:

$$
e=\frac{N}{Q}, \mathrm{~kW} \cdot \mathrm{h} / \mathrm{t}
$$

From (12), taking into account (6), we obtain the specific electrical capacity at unregulated tape speed:

$$
e=A+\frac{B v_{b}}{Q} .
$$

Similarly, substituting (9) into (12), we find the specific electric capacity with adjustable speed of the conveyor belt in the form:

$$
e=A+\frac{B g}{3.6 q_{l \max }} .
$$

From formulas (13) and (14), it follows that the specific energy capacity of the belt conveyor at an unregulated belt speed increases with an increase in the value of the load flow $Q$ entering the conveyor and decreases asymptotically as $Q \rightarrow \infty$ approaches a constant value and at regulated belt speed the specific energy capacity of the belt conveyor takes a constant value regardless of $Q$.

\section{Result and discussion}

Figures 1 and 2 show the dependencies of the drive power of the conveyor $N$ on the value of the load flow $Q$ entering to the conveyor for horizontal $\left(\alpha=0^{\circ}\right)$ and inclined $\left(\alpha=5^{\circ}\right)$ conveyors, respectively, in the case of constant speed of the conveyor belt constructed according to the formula (6) (straight line 1), and in the case of a change in belt speed, 
corresponding to the maximum linear load, constructed according to formula (9) (straight line 2). In this case, the initial data took the values: $L=1000 \mathrm{~m} ; \alpha=0^{\circ} ; \alpha=5^{\circ}$; $v_{b}=1.6 \mathrm{~m} / \mathrm{s} ; k_{1}=1.08 ; \eta=0.85 ; \omega^{\prime}=0.03 ; q_{r}{ }_{r}=245 \mathrm{~N} / \mathrm{m} ; q^{\prime \prime}{ }_{r}=88.3 \mathrm{~N} / \mathrm{m} ; q_{b}=157 \mathrm{~N} / \mathrm{m} ;$ $q_{l \max }=698.5 \mathrm{~N} / \mathrm{m} ; Q_{n}=410 \mathrm{t} / \mathrm{hr}$ (nominal productivity of the conveyor).

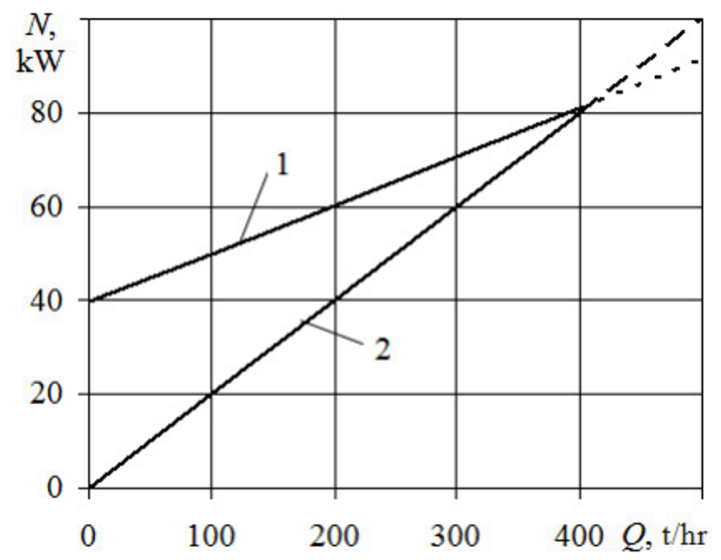

Fig. 1. Graphs of the drive power of the belt conveyor without regulation and with belt speed regulation when $\alpha=0^{\circ}$.

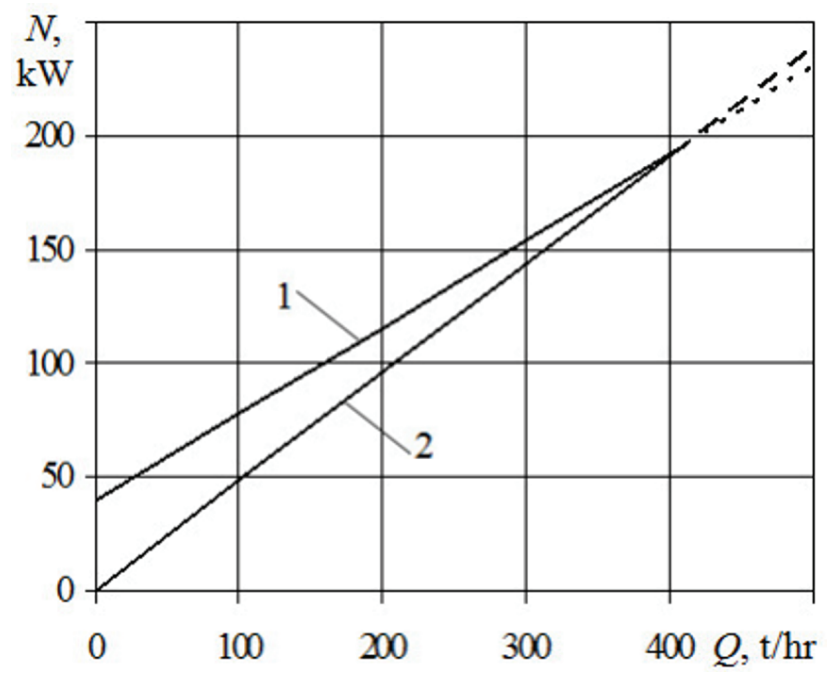

Fig. 2. Graphs of dependence of the drive power of a belt conveyor without regulation and with belt speed regulation at $\alpha=5^{\circ}$.

It can be seen from the graphs that when idling, the drive power of a horizontal belt conveyor is about $40 \%$ of the drive power at the nominal load of the conveyor (Fig. 1).

In addition, for a horizontal conveyor $\left(\alpha=0^{\circ}\right)$, the drive power going to move the load and the belt, in the case of constant belt speed (straight 1), is more than the drive power going to move the load and belt, if the speed of the conveyor belt is regulated at $q_{l}=q_{l \text { max }}$.

For an inclined conveyor $\left(\alpha=5^{\circ}\right)$ (Fig. 2) the difference between straight lines 1 and 2 is small. Therefore, for inclined conveyors, the drive power of the conveyor used to move the load, in the case of regulating the belt speed, is not significantly different from the case of an unregulated belt speed. This is due to the fact that for inclined conveyors, the drive power of the conveyor is mainly used to lift the load, while at the same time the drive 
power of the conveyor, which goes to resists the movement of the belt and load and the loss in the drive of the conveyor, is negligible.

If the belt speed regulating for horizontal and inclined conveyors is carried out using an asynchronous frequency-controlled electric motor, the induction losses in the electric motors associated with the load deviation from the nominal one are significantly reduced [2].

As the calculations showed, in the case of a two-fold reduction in the value of the load flow entering to the conveyor, the electric power loss at frequency regulation of the speed of the conveyor belt is reduced by $30 \%$ compared to the unregulated speed of the conveyor belt.

Figure 3 shows graphs of the specific energy consumption of a belt conveyor $e$ at unregulated (curve 1) and regulated $e$ (curve 2) speeds of the conveyor belt from the load flow $Q$. At the same time, the initial data assumed the same values as for the graphs in Figure 2.

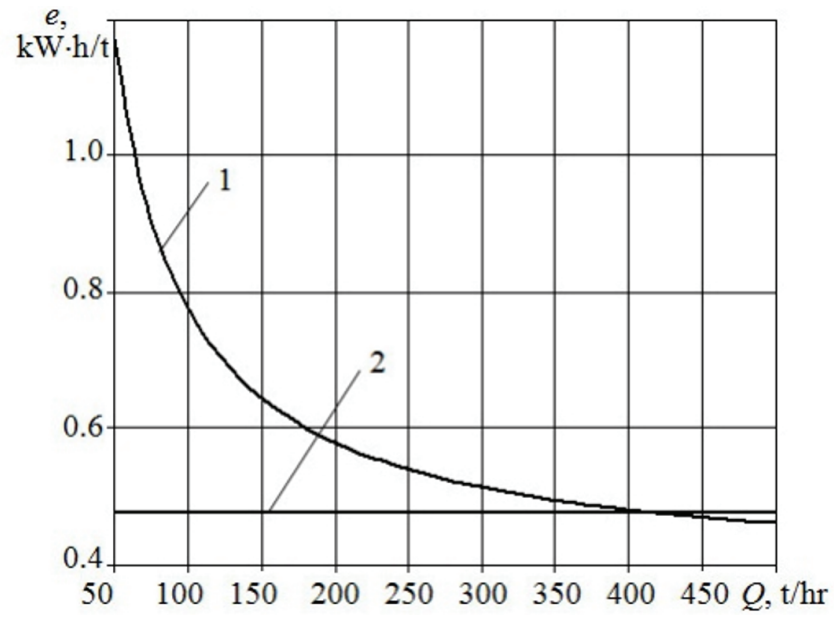

Fig. 3. Graphs of the specific energy capacity of the belt conveyor on its productivity.

From the graphs (Fig. 3) it can be seen that with an unregulated speed of the conveyor belt, the specific energy capacity of the conveyor with an increasing the load flow $Q$ entering the conveyor decreases according to a hyperbolic law and changes from infinity at $Q=0$ to a constant value $e=A$ at $Q \rightarrow \infty$. With an regulating belt speed, the specific energy capacity of the belt conveyor takes a constant value of $e=A+B g /\left(3.6 q_{l \max }\right)$ and does not depend on the productivity of the conveyor $Q$.

Consequently, regulating the speed of the conveyor belt with an asynchronous frequency-controlled electric motor under the condition of a constant maximum linear load $q_{l}=q_{l \text { max }}=$ const for a horizontal conveyor significantly reduces drive power losses during movement of the load and the conveyor belt, and for an inclined conveyor it significantly reduces induction losses of electric motors at high power factor $\cos \varphi$.

For a conveyor transport system with a complex branched structure and with a large number of conveyors and bunkers, the average specific energy capacity $E(\mathrm{~kW} \cdot \mathrm{h} / \mathrm{t})$ equal to the ratio of the average throughput to the average energy capacity of the transportation system is taken as an energy efficiency criterion, which according to $[8,9]$ is determined by the formula:

$$
E=\frac{w_{c}}{60 m_{c}}
$$


where $w_{c}$ is the average energy capacity of transportation of the conveyor transport system, $\mathrm{kW} ; m_{c}$ is the average throughput of the conveyor transport system, $\mathrm{t} / \mathrm{min}$.

Figure 4 shows graphs of the specific energy capacity of transportation $E$ of the conveyor-bunker-conveyor system versus the average value of the load flow $m_{Q}$ entering to the over-bunker conveyor in the case of an uncontrollable bunker at a constant speed of the bunker conveyor belt (curve 1) and when regulating the speed of the bunker conveyor belt at various nominal productivity of the over-bunker conveyor $Q_{m 1}$, equal respectively to $Q_{m 1}=5 ; 6 ; 7 \mathrm{t} / \mathrm{min}$ (curves 2, 3, 4).

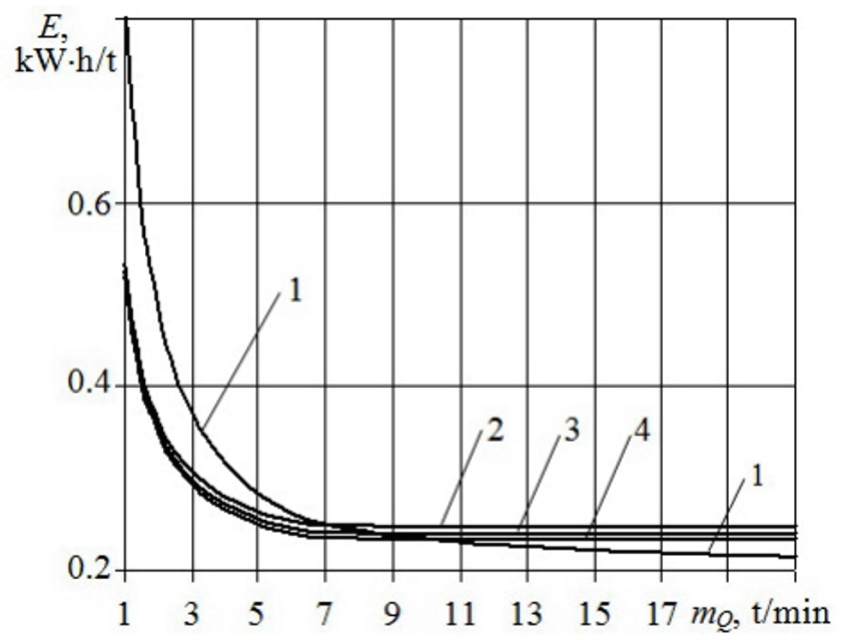

Fig. 4. Graphs of specific energy capacity $E$ of the conveyor-bunker-conveyor system versus the average value of the $m_{Q}$.

In addition, in the case of regulating the speed of the belt the over the bunker conveyor, its linear load $q_{l 1}(\mathrm{~N} / \mathrm{m})$ took the maximum value and according to (7) was determined by the formula:

$$
q_{l 1}=q_{l 1 \max }=\frac{60 Q_{m 1} g}{3.6 v_{b m 1}},
$$

where $v_{b m 1}$ is the maximum allowable speed of the over-bunker conveyor belt, $\mathrm{m} / \mathrm{s}$.

In this case, the speed of the over-bunker conveyor belt, depending on the load flow $m_{Q}$, arriving at it is equal to

$$
v_{b 1}=\frac{m_{Q}}{Q_{m 1}} v_{b m 1} .
$$

Graphs in Figure 4 were built with the following initial data: the intensity of downtime and recovery of the over-bunker conveyor is $\lambda_{1}=0.025 \mathrm{~min}^{-1} ; \mu_{1}=0.0614 \mathrm{~min}^{-1}$, and the under-bunker one $\lambda_{2}=0.017 \mathrm{~min}^{-1} ; \mu_{2}=0.069 \mathrm{~min}^{-1}$, bunker volume $V=100 \mathrm{~m}^{3}$, feeder speed $Q_{n}=6 \mathrm{t} / \mathrm{min}$; the parameters of the over-bunker and under-bunker conveyors are $L_{1}=$ $=L_{2}=300 \mathrm{~m} ; \alpha_{1}=\alpha_{2}=2^{\circ} ; q_{l 1 \max }=q_{l 2 \max }=712 \mathrm{~N} / \mathrm{m} ; q_{r 1}^{\prime}=q_{r 2}^{\prime}=250 \mathrm{~N} / \mathrm{m} ; q^{\prime \prime}{ }_{r 1}=q_{r 2}{ }_{r 2}=$ $=90 \mathrm{~N} / \mathrm{m} ; q_{b 1}=q_{b 2}=160 \mathrm{~N} / \mathrm{m} ; \omega_{1}^{\prime}=\omega_{2}^{\prime}=0.03 ; k_{1}=k_{2}=1.3 ; \eta_{1}=\eta_{2}=0.85$. At the same time, the nominal speeds of the over-bunker and under-bunker conveyors are $v_{b m 1}=v_{b m 2}=$ $=1.6 \mathrm{~m} / \mathrm{s}$. 
From Figure 4 it can be seen that at $m_{O}<6.8 \mathrm{t} / \mathrm{min}$, the specific energy capacity of the conveyor-bunker-conveyor system $E$ in the case of regulating belt speed is $23 \%$ less than in case of unregulated speed of the conveyor. If the value of the load flow arriving at the over-bunker conveyor is $m_{O} \geq 6.8 \mathrm{t} / \mathrm{min}$, then the specific energy capacity of the conveyorbunker-conveyor system $E$ with an unregulated and regulated belt speed of the over-bunker conveyor takes a constant value regardless of the load flow $m_{Q}$ to the over-bunker conveyor, and does not depend on the nominal productivity of the over-bunker conveyor $Q_{m 1}$.

\section{Conclusions}

1. When regulating the speed of the conveyor belt at a constant maximum linear load on the belt, if the load flow to the conveyor is halved, the electric power loss when regulating the speed of the conveyor belt is reduced by $30 \%$ compared to the loss at an unregulated belt speed. In the case of regulating the speed of the conveyor belt, the specific energy capacity of the conveyor belt takes a constant minimum value, independent of the value of the load flow entering the conveyor.

2. When regulating the speed of the conveyor belt of the over-bunker conveyor of the conveyor-bunker-conveyor system, the average and specific energy capacity of this system are reduced on average by $23 \%$ than at the constant speed of the over-bunker conveyor belt.

\section{References}

1. Babokin, G.I. (2002). Energy saving in the electric drive of the conveyor. Izv. Universities. Mountain Journal, 1, 122-125

2. Braslavsky, I.Ya., Ishmatov, Z.h., Polyakov, V.N. (2004). Energosberegayushchiy asinkhronnyu elektroprivod. Moskva: Isdatelskiy tsentr "Akademiya"

3. Lauhoff, H. (2006). Do regulating the speed of belt conveyors really help save energy? Glukauf, 1, 9-16

4. Kucheryavenko, V.F., Semchenko, A.A. (2008). The regulated conveyor is the basis for increasing the efficiency of transportation of the rock mass. Glukauf, 1, 58-63

5. Kozar, A.V. (2011). Increasing the energy efficiency of belt conveyors of coal mines. Proc. of the International scientific conference "Forum of Mining Engineers", National Mining University, Dnipropetrovsk, October, 182-186

6. Tarasov, V.I. (2015). Evaluation of belt conveyor perfection by an energy indicator. Rozrobka rodovishch: shchorichnyi naukovo-tekhnichnyi zbirnyk, 155-161

7. Shachmeister, L.G., Dmitriev, V.G. (1987). Teorya i raschet lentochnyh konveerov. Moskva: Mashinostroenie

8. Kiriya, R.V. (2013). Definition of the criterion of the efficiency of functioning of the systems of underground conveyor transport of coal mines. Naukovi visti. Suchasni problemy $v$ metalurgii, 16, 13-21

9. Kiriya, R.V., Mishchenko T.F. (2015). Definition of the carrying capacity and energy intensity of transportation of the rock mass by conveyor transport of coal mines. Zbirnyk naukovykh prats Natsionalnogo girnychogo universytetu, 46, 96-104 